ARTICLE

\title{
Chiral phosphoric acid-catalyzed stereodivergent synthesis of trisubstituted allenes and computational mechanistic studies
}

Jiawen Wang ${ }^{1,2,4}$, Sujuan Zheng ${ }^{3,4}$, Subramani Rajkumar ${ }^{1}$, Jinglei $\mathrm{Xie}^{1}, \mathrm{Na} \mathrm{Yu}^{1}$, Qian Peng $\mathbb{1}^{3 凶} \&$ Xiaoyu Yang (1) ${ }^{1 凶}$

Chiral molecules with multiple stereocenters are widely present in natural products and pharmaceuticals, whose absolute and relative configurations are both critically important for their physiological activities. In spite of the fact that a series of ingenious strategies have been developed for asymmetric diastereodivergent catalysis, most of these methods are limited to the divergent construction of point chirality. Here we report an enantioselective and diastereodivergent synthesis of trisubstituted allenes by asymmetric additions of oxazolones to activated 1,3-enynes enabled by chiral phosphoric acid (CPA) catalysis, where the divergence of the allenic axial stereogenicity is realized by modifications of CPA catalysts. Density functional theory (DFT) calculations are performed to elucidate the origin of diastereodivergence by the stacking- and stagger-form in the transition state (TS) of allene formation step, as well as to disclose a Münchnone-type activation mode of oxazolones under Brønsted acid catalysis.

\footnotetext{
${ }^{1}$ School of Physical Science and Technology, ShanghaiTech University, Shanghai 201210, China. ${ }^{2}$ University of Chinese Academy of Sciences, 100049 Beijing, China. ${ }^{3}$ State Key Laboratory of Elemento-Organic Chemistry, College of Chemistry, Nankai University, 300071 Tianjin, China. ${ }^{4}$ These authors contributed equally: Jiawen Wang, Sujuan Zheng. ${ }^{凶}$ email: qpeng@nankai.edu.cn; yangxy1@shanghaitech.edu.cn
} 
C hiral allenes are featured in many biologically active natural products, pharmaceuticals, and functional materials ${ }^{1,2}$. In addition, they also serve as versatile building blocks in organic synthesis due to their diverse reactivities ${ }^{3}$. Despite of the high demands of chiral allenes, the asymmetric catalytic synthesis of these axially chiral compounds remains a challenge in organic synthesis ${ }^{4-6}$. In the last two decades, a number of elegant asymmetric catalytic strategies have been developed for chiral allene synthesis, such as nucleophilic additions of 1,3-enynes ${ }^{7-19}$, dynamic kinetic asymmetric transformations (DyKAT) of racemic allenes ${ }^{20-22}$, rearrangement of alkynes ${ }^{23-25}$, coupling of alkynes with diazo compounds ${ }^{26-28}$ and others $^{29-31}$. Among these strategies, the direct asymmetric additions of prochiral 1,3-enynes represent as one of the most attractive strategies for synthesis of multiple-substituted chiral allenes, owing to the easy accessibility of these substrates. Since the pioneer work of enantioselective synthesis of boryl, silyl and aryl allenes via chiral $\mathrm{Pd}$ and $\mathrm{Rh}$ catalyzed asymmetric additions of 1,3-enynes by Hayashi and co-workers ${ }^{7-9}$, a series of elegant asymmetric reactions have been developed employing this strategy, either through asymmetric transition metal-catalysis ${ }^{7-14}$ or organocatalysis $^{15-19}$ (Fig. 1a).
Chiral molecules with multiple stereocenters are widely present in natural products and pharmaceuticals, whose absolute and relative configurations are both critically important for their physiological activities. In the past few decades, numerous highly enantioselective and diastereoselective reactions have been developed. However, modulation the sense of diastereoselectivity in an asymmetric catalytic reaction is still challenging, because the diastereochemical preference is largely governed by the inherent structure and stereoelectronic nature of the substrates ${ }^{32}$. To address this intrinsic problem, a series of ingenious strategies have been developed for asymmetric diastereodivergent catalysis $^{33-35}$, such as using distinct catalysts ${ }^{36-38}$, change of metal cations $^{39}$, and ligands ${ }^{40,41}$ of the catalysts, change of reaction conditions ${ }^{42,43}$, stereodivergent dual catalysis ${ }^{44-50}$ and stepwise control $^{51-54}$. Nevertheless, achieving asymmetric diastereodivergent catalysis through modifications of one single type of chiral catalysts remains elusive $e^{55,56}$.

Despite the fact that a large number of asymmetric stereodivergent catalytic methods have been developed, most of these methods have been limited to the construction of point stereogenicity divergence, while stereodivergent synthesis of axial stereogenicity has been rarely explored, except using stepwise

a<smiles>[R7]C#C/C([R2])=C\[R8][B-]</smiles>
$\mathrm{R}=-\mathrm{SiR}_{3},-\mathrm{Ar},-\mathrm{BR}_{2},-\mathrm{NR}_{2}$, enolate $\ldots$.

b

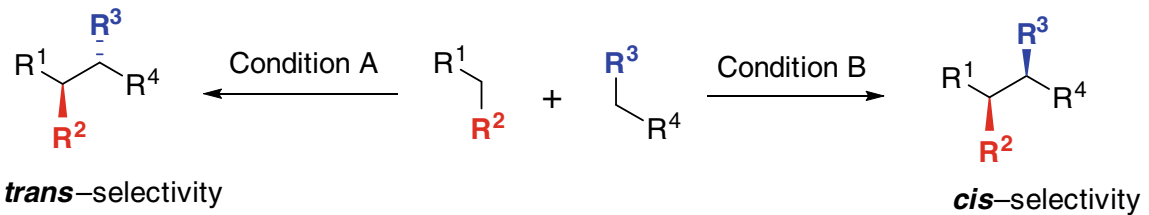

Mostly limited to construction of point stereogenicity divergence.

C<smiles>[R]C#CC(=C[R])C([R])=O</smiles>

cat. A<smiles>[R]C(=O)C(=C=C)C([R7])C1([R7])N=C(P)OC1=O</smiles>

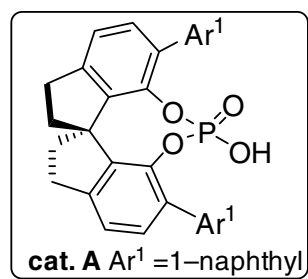

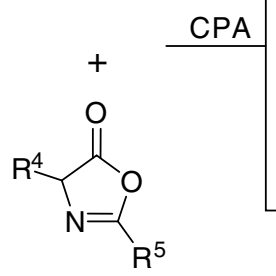

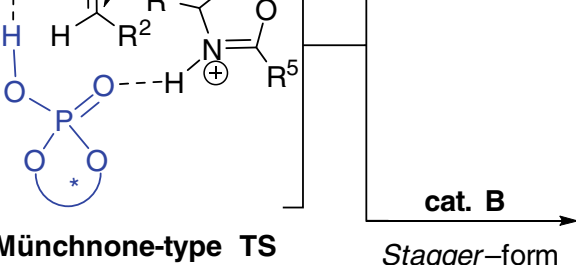<smiles>[R]C=C=C(C([R])=O)C([R7])[C@]1([R7])N=C([R8])OC1=O</smiles>

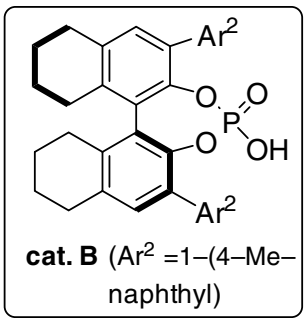

- Enantioselective and diastereodivergent synthesis of axial stereogenicity

- Diastereodivergent synthesis via modifications of CPA catalysts

Fig. 1 Asymmetric synthesis of chiral allenes and stereodivergent synthesis. a Asymmetric synthesis of chiral allenes via enantioselective additions of activated 1,3-enynes. b Asymmetric stereodivergent catalysis was limited to the construction of point stereogenicity divergence. c Asymmetric stereodivergent construction of axial stereogenicity via modifications of chiral phosphoric acid catalysts. 
control strategy ${ }^{53,54}$ (Fig. 1b). Herein, we report an enantioselective and diastereodivergent synthesis of trisubstituted allenes via asymmetric conjugate additions of activated 1,3-enynes by oxazolones ${ }^{57-60}$ enabled by CPA catalysis, in which the diastereodivergent construction of the allenic axial chirality is realized by modifications of CPA catalysts (Fig. 1c). In addition, the origin of the diastereodivergence is well elucidated by DFT calculations, in which a Münchnone-type activation mode of oxazolones under Brønsted acid catalysis is presented.

\section{Results}

Reaction optimizations. We commenced our study by selecting $\alpha$-alkynyl- $\alpha, \beta$-enone 1a and 2-para-methoxyphenyl (PMP) substituted oxazolone $\mathbf{2 a}$ as model substrates under CPA catalysis (Table 1). Under the promotion of TRIP catalyst (CPA A1, 10 mol\%) in toluene (with $3 \AA$ molecular sieves) at room temperature, only two diastereomeric allene products among the four potential ones were detected (Table 1, entry 1), albeit with both poor diastereomeric ratio (dr, 3a:4a 1:2.8) and enantiomeric excess (ee). Subsequently, a series of BINOL and H8-BINOL derived CPA catalysts were screened (entries 2-7). Satisfyingly, the 1-(4-Me-naphthyl) substituted H8-BINOL-derived catalyst B2 provided the allene product in 91\% yield with both high diastereoselectivity and enantioselectivity (3a:4a 10:1, 87\% ee, entry 7). However, surprisingly, switching the chiral scaffold of 1-naphthyl substituted CPA catalyst form H8-BINOL-type to SPINOL-type (CPA C1) led to the reversal of diastereoselectivity (3a:4a 1:11, entry 8 ) and formation of product $4 \mathbf{a}$ with high ee as well, albeit with moderate yield. To obtain better stereoselectivity control and improve the yield, the effect of the $\mathrm{R}$ group at the 2-position of oxazolone was exploited (see Supplementary Table 1), which indicated that 3,5-dimethoxyphenyl group was the optimal one (entry 9 and 10). Finally, a variety of solvents were also screened, and $\mathrm{CCl}_{4}$ was chosen as the optimal solvent (see Supplementary Table 1 for details), in which the chiral allene 3a was obtained in 98\% yield, 20:1 dr (3a:4a) with 91\% ee in the presence of CPA B2, while diastereomeric chiral allene 4 a was generated in $85 \%$ yield, $12: 1 \mathrm{dr}$ (4a:3a) with $98 \%$ ee under the catalysis of CPA C1 (entries 11-12).

Substrate scope. Having established the optimal conditions for stereodivergent synthesis of chiral trisubstituted allenes via modifications of CPA catalysts, the substrate scope under the catalysis of CPA (S)-B2 was firstly investigated (Fig. 2). Various substituted phenylacetylenyl groups were well tolerated under the optimal conditions, regardless of the electronic nature and positions of the substitutions, affording the allene products $\mathbf{3 a}-\mathbf{3 h}$ with high diastereoselectivities $(>7: 1)$ and enantioselectivities. In addition, substitutions of the $\mathrm{R}^{1}$ group with heteroaryl, alkenyl and alkyl groups were also amenable, which yielded the products

Table 1 Optimizations of reaction conditions ${ }^{a}$.<smiles>CC(=O)/C(C#Cc1ccccc1)=C\c1ccccc1</smiles>

1a<smiles>[R]C1=NC(CC)C(=O)O1</smiles>

$2 a$

R

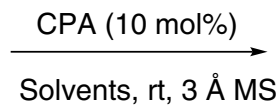<smiles>[R]C1=NC([C](CC)[C@@H](C(C)=O)c2ccccc2)C(=O)O1</smiles>

$3 a$

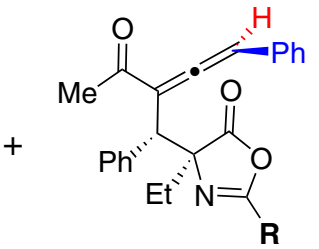

$4 \mathrm{a}$<smiles>[R]c1cc2ccccc2c(-c2c(OP(=O)(O)O)c([R])cc3ccccc23)c1O</smiles>

A1, BINOL, $\mathrm{R}^{\prime}=2,4,6-(\mathrm{iPr})_{3} \mathrm{C}_{6} \mathrm{H}_{2}$

A2, BINOL, $\mathrm{R}^{\prime}=\mathrm{Ph}$

A3, BINOL, R' = 2-naphthyl

A4, BINOL, R' = 1-naphthyl

A5, BINOL, $R^{\prime}=$ 9-anthracenyl

B1, H8-BINOL, R' = 1-naphthyl

B2, H8-BINOL, R' = 1-(4-Me-naphthyl)

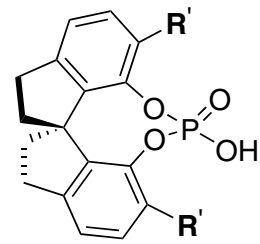

C1, R' = 1-naphthyl

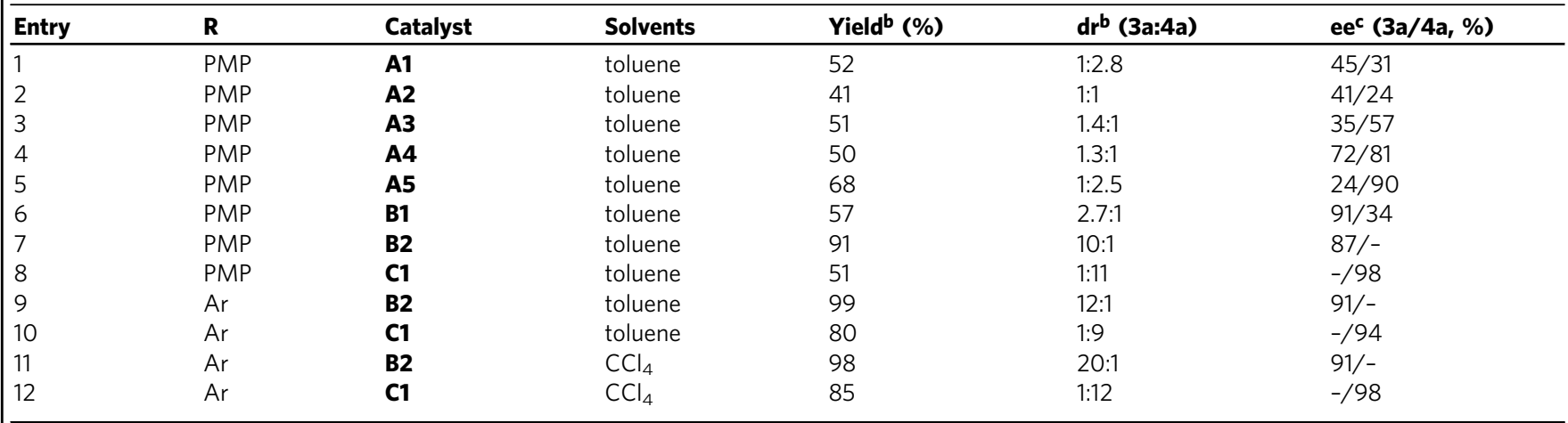

aReactions were performed with $\mathbf{1 a}(0.15 \mathrm{mmol}), \mathbf{2 a}(0.1 \mathrm{mmol})$, cat $(0.01 \mathrm{mmol}), 3 \AA \mathrm{MS}(100 \mathrm{mg})$, solvents $(0.5 \mathrm{~mL})$ at ambient temperature for $24 \mathrm{~h}$

bYields and $\mathrm{dr}$ value were determined by crude ${ }^{1} \mathrm{H}$ NMR analysis using 1,2-dimethoxyethane (DME, $0.1 \mathrm{mmol}$ ) as internal standard.

${ }^{c}$ ee values were determined by HPLC analysis on a chiral stationary phase. PMP $=$ para-methoxylphenyl, $\mathbf{A r}=3,5$-dimethoxyphenyl. 
<smiles>[R]C#CC(=C[R])C([R])=O</smiles>

1<smiles>[Z8]C1N=C(Br)OC1=O</smiles>

(S)-B2 (10 mol\%)

$3 \AA \mathrm{MS}, \mathrm{CCl}_{4}$, rt<smiles>[R]C(=O)C(=C=C[3H])C([R7])[C@]1([R7])N=C([Al])OC1=O</smiles>

3 (major)<smiles>[R]C(=O)/C(=C/[3H])[C@@H]([R7])[C@H]1N=C([Al])OC1=O</smiles>

4 (minor)<smiles>CCC(/C(=C/c1ccc(P)cc1)C(C)=O)C1(c2ccccc2)N=C([Al])OC1=O</smiles>

3a, $\mathrm{R}=\mathrm{H}, 75 \%, 20: 1 \mathrm{dr}, 91 \%$ ee 3b, $R=M e, 67 \%, 16: 1 \mathrm{dr}, 91 \%$ ee 3c, $\mathrm{R}=\mathrm{Cl}, 64 \%, 10: 1 \mathrm{dr}, 90 \%$ ee 3d, $R=O M e, 53 \%, 11: 1 \mathrm{dr}, 91 \%$ ee 3e, $R=F, 62 \%, 9: 1 \mathrm{dr}, 90 \%$ ee 3f, $R=\mathrm{CF}_{3}, 59 \%, 7: 1 \mathrm{dr}, 88 \%$ ee<smiles>CC[C@H](c1ccccc1)C(C(=Cc1ccsc1)C(C)=O)C1N=C([Al])OC1=O</smiles>

3i, $56 \%, 5: 1 \mathrm{dr}, 92 \%$ ee<smiles>[R]C(=O)C(=C=Cc1ccccc1)[C@@H](c1ccc([R])cc1)[C@H]1N=C([Ga])OC1=O</smiles>

3I, $\mathrm{R}=\mathrm{Me}, 59 \%, 12: 1 \mathrm{dr}, 90 \%$ ee $3 \mathrm{~m}, \mathrm{R}=\mathrm{F}, 60 \%, 9: 1 \mathrm{dr}, 92 \%$ ee 3n, $\mathrm{R}=\mathrm{Cl}, 64 \%, 9.4: 1 \mathrm{dr}, 92 \%$ ee 3o, $\mathrm{R}=\mathrm{OMe}, 63 \%, 9: 1 \mathrm{dr}, 89 \%$ ee<smiles>CCC(=O)C(=C=Cc1ccccc1)C(c1ccccc1)[C@@H](CC)c1ccccc1</smiles>

$3 r, 63 \%, 9.4: 1 \mathrm{dr}, 98 \%$ ee<smiles>[CH2]C([Ge])=N[C@@H](c1ccccc1)[C@@H](C(=C=Cc1ccccc1)C(C)=O)c1ccccc1</smiles>

3v, $67 \%, 3.7: 1 \mathrm{dr}, 95 \%$ ee<smiles>CC(=O)C(=CC1=CCCCC1)C(C(C)=O)C1N=C([Al])OC1=O</smiles>

3j, $66 \%, 14: 1 \mathrm{dr}, 92 \%$ ee

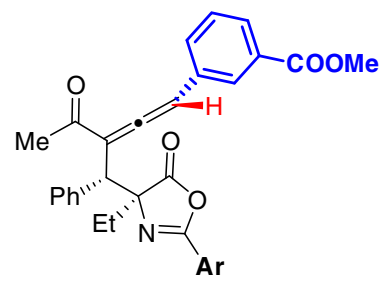

$3 g, 65 \%, 9.5: 1 \mathrm{dr}, 90 \%$ ee<smiles>CCCCCCCCCCCCCCCCC(=O)C(C)=O</smiles>

3k, $48 \%, 5: 1 \mathrm{dr}, 92 \%$ ee<smiles>CC(=O)/C(=C\C=C/c1ccccc1)[C@H](c1ccc2ccccc2c1)[C@@H]1N=C([Al])OC1=O</smiles>

3p, $59 \%, 13: 1 \mathrm{dr}, 90 \%$ ee<smiles>CCCCC(=O)C(=Cc1ccccc1)C(c1ccccc1)C1N=C(Br)OC1=O</smiles>

3t, $61 \%, 20: 1 \mathrm{dr}, 99 \%$ ee<smiles>CSCC[C@]1([C@@H](C(=C=Cc2ccccc2)C(C)=O)c2ccccc2)N=C([Al])OC1=O</smiles>

$3 \mathbf{x}, 59 \%, 4.8: 1 \mathrm{dr}, 91 \%$ ee<smiles>CCC1N=C([Ge])OC1=C=Cc1ccccc1Cl</smiles>

3h, $64 \%, 16: 1 \mathrm{dr}, 90 \%$ ee

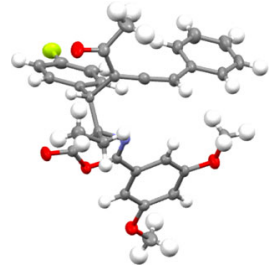

X-ray strcuture of $( \pm)-3 m$<smiles>CCC1N=C([Al])OC1=O</smiles>

3q, $38 \%, 4: 1 \mathrm{dr}, 93 \%$ ee<smiles>CCC1N=C([Al])OC1=O</smiles>

3u, $63 \%,>25: 1 \mathrm{dr}, 98 \%$ ee

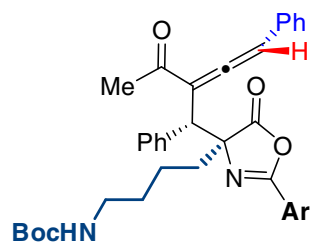

3y, $67 \%, 5.6: 1 \mathrm{dr}, 89 \%$ ee

Fig. 2 Scope for asymmetric synthesis of trisubstituted allenes $\mathbf{3}$ catalyzed by CPA catalyst (S)-B2. Unless otherwise noted, reactions were performed with $1(0.15 \mathrm{mmol}), \mathbf{2}(0.1 \mathrm{mmol}),(S)$-B2 catalyst $(0.01 \mathrm{mmol})$ and $3 \AA \mathrm{MS}(100 \mathrm{mg})$ in $\mathrm{CCl}_{4}(0.5 \mathrm{~mL})$ at room temperature for $24 \mathrm{~h}$. Yields were isolated yields of allenes 3. Dr values were determined by crude ${ }^{1} \mathrm{H}$ NMR analysis. Ee values were determined by HPLC analysis on a chiral stationary phase. Ar $=$ 3,5-dimethoxyphenyl. 
with high enantioselectivities, albeit with moderate to high diastereoselectivity control ( $3 \mathbf{i}-\mathbf{3 k}$ ). Next, a range of $\mathrm{R}^{2}$ groups at the $\beta$-positions of the enones were explored, which suggested that various substituted aryl groups (3l-3p) were well tolerated, as well as an alkyl group, albeit with moderate dr value (3q). The relative configurations of the allene products 3 were assigned by analogy to $\mathbf{3 m}$, whose relative structure was confirmed by X-ray crystallography. Subsequently, a range of groups at the ketone site $\left(\mathrm{R}^{3}\right)$ were also investigated, where the Et-substituted, $n \mathrm{Pr}$-substituted, $n \mathrm{Bu}$-substituted, and $i \mathrm{Bu}$-substituted substrates all generated the chiral allenes with both excellent enantioselectivitie and diastereoselectivitie $(>9.4: 1 \mathrm{dr},>98 \%$ ee, $3 \mathbf{r}-3 \mathbf{3 u})$. Finally, a series of substitutions (including some functional group-containing substituents) at the 4-position of oxazolones were also exploited under the optimal conditions, which indicated that the chiral allene products could be produced with high enantioselectivities, albeit with a bit erosive diastereoselectivities (3.7:1-5.6:1, 3v-3y).

After investigation of the scope under $(S)$-B2 catalysis, the substrate scope generality with catalyst $(R)$-C1 was also studied (Fig. 3). All the $\mathrm{R}^{1}, \mathrm{R}^{2}$ and $\mathrm{R}^{4}$ substituted substrates explored in Fig. 2 were subjected into investigation under the catalysis of $(R)$ C1 catalyst, which generated the diastereomeric allenes 4 as the major products with both high $\mathrm{dr}$ and ee values for most cases $(4 \mathbf{a}-4 \mathbf{y})$. The absolute structures of the chiral allenes 4 were assigned by analogy to product $\mathbf{4 c}$, whose absolute configuration was unambiguously confirmed by X-ray crystallography. Unfortunately, the variations of the $\mathrm{R}^{3}$ groups of $\alpha$-alkynyl- $\alpha, \beta$-enone 1 under standard conditions were not well tolerated, which led to<smiles>[R7]C#CC(=C[R])C([R])=O</smiles>

1<smiles>[Z8]C1N=C([Al])OC1=O</smiles>

2
(R)-C1 (10 mol\%) $3 \AA \mathrm{MS}, \mathrm{CCl}_{4}$, rt<smiles></smiles>

4 (major)<smiles>[R]C(=O)/C(=C/C=[R]([H])[H])[C@@]1([R7])N=C([Ge])OC1=O</smiles>

3 (minor)

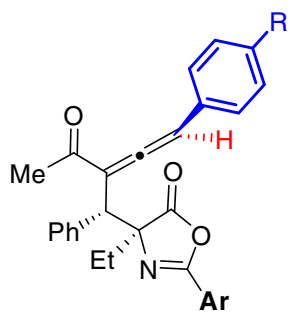

4a, $\mathrm{R}=\mathrm{H}, 69 \%, 12: 1 \mathrm{dr}, 97 \%$ ee

4b, $R=$ Me, $59 \%, 7: 1 \mathrm{dr}, 96 \%$ ee

4c, $\mathrm{R}=\mathrm{Cl}, 64 \%, 8.5: 1 \mathrm{dr}, 98 \%$ ee

4d, $R=$ OMe, $48 \%, 6.4: 1 \mathrm{dr}, 96 \%$ ee

4e, $R=F, 62 \%, 10: 1 d r, 97 \%$ ee

4f, $R=\mathrm{CF}_{3}, 62 \%, 7: 1 \mathrm{dr}, 98 \%$ ee<smiles>CCC1=NC(=O)C(=Cc2ccccc2Cl)C1[C@@H](C(C)=O)c1ccccc1</smiles>

4h, 53\%, 4.7:1 dr, 96\% ee

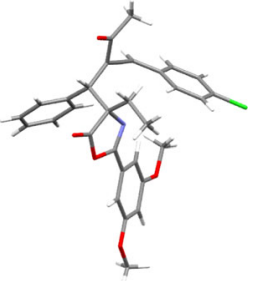

X-ray structure of $4 c$<smiles>CCC1=NC(C(c2ccccc2)c2ccccc2)C(C(C)=O)=C1C1=CCCCC1</smiles>

4j, 54\%, 15:1 dr, 97\% ee<smiles>C#CC1=NC([C@@H](C(=Cc2cccc(C(=O)OC)c2)C(C)=O)c2ccccc2)C(=O)O1</smiles>

4g, $72 \%, 13: 1 \mathrm{dr}, 97 \%$ ee<smiles>CCCCCCCCCCCCCCC(=O)C(C)=O</smiles>

4k, $67 \%, 13: 1 \mathrm{dr}, 95 \%$ ee

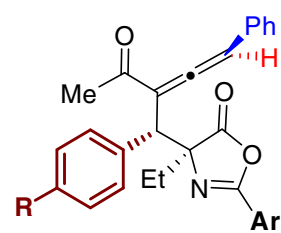

4I, $R=$ Me, $65 \%, 14: 1 d r, 96 \%$ ee $4 \mathrm{~m}, \mathrm{R}=\mathrm{F}, 78 \%, 11: 1 \mathrm{dr}, 94 \%$ ee 4n, $\mathrm{R}=\mathrm{Cl}, 76 \%, 12: 1 \mathrm{dr}, 97 \%$ ee 4o, $R=$ OMe, $78 \%, 14: 1 \mathrm{dr}, 95 \%$ ee

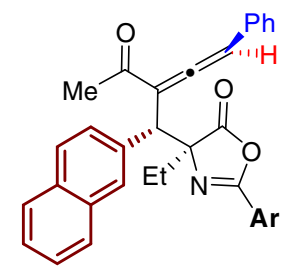

$4 p, 59 \%, 11: 1 d r, 97 \%$ ee

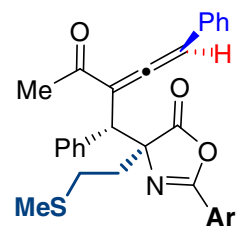

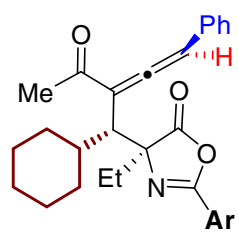

4q, $50 \%, 13: 1 \mathrm{dr}, 99 \%$ ee

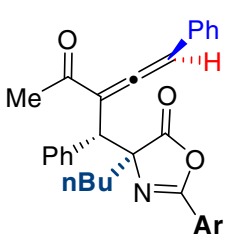<smiles>CC(=O)C(=C=Cc1ccccc1)[C@@H](c1ccccc1)[C@@]1(Cc2ccccc2)N=C([Ga])OC1=O</smiles>

4w, $77 \%, 16: 1 \mathrm{dr},>99 \%$ ee

4x, 63\%, 8:1 dr, 94\% ee<smiles>CCC1=N[C@](CCCCNC(=O)OCc2ccccc2)([C@@H](/C(=C/C(=O)c2ccccc2)C(C)=O)c2ccccc2)C(=O)O1</smiles>

$4 \mathbf{v}, 67 \%, 20: 1 \mathrm{dr}, 99 \%$ ee

Fig. 3 Scope for asymmetric synthesis of trisubstituted allenes $\mathbf{4}$ catalyzed by CPA catalyst (R)-C1. Unless otherwise noted, the reaction conditions were the same with those indicated in Fig. 2, except ( $R$ - -C1 catalyst (10 mol\%) was used instead. $\mathbf{A r}=3,5$-dimethoxyphenyl. 
very low yields and decreased diastereoselectivities (see Supplementary Fig. 1 for details).

Reaction mechanism and origin of diastereodivergence. To investigate the origin of diastereodivergence in construction of the allenic axial chirality, a control experiment was performed. In the presence of CPA catalysts $(S)-\mathbf{B} 2$ and $(R)-\mathbf{C 1}$, respectively, the asymmetric isomerization of racemic $\alpha$-alkynyl ketone ${ }^{23} \mathbf{5 a}$ proceeded efficiently to give the chiral trisubstituted allene $\mathbf{6 a}$ in the opposite enantiomeric bias (Fig. 4a). In addition, some control experiments of the stabilities of the chiral allene products under various conditions were performed (see Supplementary Fig. 2), which indicated that the conversion from a kinetic epimer to a thermodynamic epimer under the reaction conditions is probably not likely. Based on these results and previous reports ${ }^{16-18}$, a preliminary stepwise mechanism was proposed: (1) oxazolones were activated by CPA catalyst via tautomerism to form active enol intermediates; (2) the Michael addition of $\alpha$-alkynyl enones by the activated oxazolone intermediates generated another enol intermediates INT A stereoselectively under the guidance of CPA catalysts; (3) the CPA catalyst mediated the proton transfer ${ }^{61,62}$ of INT A to generate products with the allenic axial stereogenicity (Fig. 4b). For the stereoselectivities of these reactions, we presumed that both $(S)$-H8-BINOL-B2 and $(R)$-SPINOL-C1 catalyst generated the same $(S, R)$-syn-configuration in the Michael addition step, which was followed by the proton transfer step to afford the distinct axial chirality of $(S, R, R)$-product or $(S, R, S)$-product, respectively.

To unveil the different stereochemical control of CPA catalysts in Michael addition and proton transfer steps, density functional theory (DFT) calculations were performed at M06-2X/6-311+ $+\mathrm{G}(\mathrm{d}, \mathrm{p}) / / \mathrm{M} 06-2 \mathrm{X} / / 6-31 \mathrm{G}(\mathrm{d})$ level of theory ${ }^{63-65}$ (see Supplementary Data 1 for Cartesian coordinates of the optimized structures). Surprisingly, based on a well-accepted enol-type mode (mode A) of oxazolones 57,58 , initial calculations of the Michael addition step using an achiral phosphoric acid catalyst (dimethyl phosphate, DMP) provided the anti-addition predication of stereochemical outcomes, which were not in agreement with the experimental syn-addition results (Fig. 4c). Further computational evaluations using chiral $(S)$-B2 and $(R)$-C1 catalysts remain the wrong $(R, R)$-anti-addition prediction as well, suggesting that the diastereoselectivity of the Michael addition step did not rely on the chiral scaffolds of CPA catalysts (see Supplementary Fig. 4). Inspired by the basicity of related functional groups of oxazolone, the imine part of oxazolones acting as proton accepter in hydrogen bonding with CPA catalyst is more accessible rather than the carbonyl group (see Supplementary Fig. 4a). Therefore, a Münchnone-type mode $59,60,66$ (mode B) was proposed and the correct syn-addition outcomes were achieved depended on the achiral DMP catalyst (Fig. 4c). The calculation results suggested that transition state (TS) of enol-type requires $6.1 \mathrm{kcal} / \mathrm{mol}$ more activation energy than that of the Münchnone-type by achiral DMP catalyst in the prototropic activation step. For the Michael addition step, Münchnone-type model is also superior to enoltype one. And among a number of our calculated Newman conformations (see Supplementary Table 2), the most favored conformation of syn-addition-TS in Münchnone-type is more stable than the most favored conformation of anti-addition-TS in enol-type by $4.2 \mathrm{kcal} / \mathrm{mol}$, indicating this diastereoselectivity is highly model dependent. The calculations, based on chiral (S)-B2 and $(R)-\mathbf{C l}$ catalysts, provided similar results that phosphoric acid catalysts tend to activate oxazolones in a fashion of Münchnonetype mechanism in these reactions, leading to syn-addition products for the diastereoselectivities (see Supplementary Figs. 3 and 4).
The energy profile of Münchnone-type mechanism was performed in Fig. 4d. Because only the Michael addition and proton transfer steps are responsible for the chirality control in these reactions, the prototropic activation steps forming the key precursor INT2 were not shown here (for the details of these steps see Supplementary Fig. 3). From the related INT2-C/-B, the activated 1,3-enyne 1a undergoes a nucleophilic attack by Münchnone-type intermediate of oxazolone via TS2 accompanying the proton delivery of CPA catalyst. There are four major transition states with different chiral features located, namely synisomers (TS2-RS, TS2-SR), anti-isomers (TS2-RR, TS2-SS). Although the CPA catalysts of $(S)$-B2 and $(R)-\mathbf{C 1}$ provide quite similar chiral cavities, they surprisingly display distinct modes of stereoselectivity control in both Michael-addition and proton transfer steps depended on the flexible BINOL backbone and rigid SPINOL backbone, respectively. For (S)-H8-BINOL-B2 catalyst, the final configuration of product Pro-SRR is determined by the proton transfer step with $1.7 \mathrm{kcal} / \mathrm{mol}$ free energy difference after the facile and reversible Michael-addition step. Due to sterically repulsive interactions between the phenyl group $\left(\mathrm{R}^{2}\right)$ at the $\beta$-position of $1 \mathrm{a}$ and the ethyl group of $\mathbf{2 a}$, the TS2-B$\boldsymbol{R S}$ is unstable for $1.9 \mathrm{kcal} / \mathrm{mol}$ comparing to the favorable TS2-B$\boldsymbol{S R}$ that is supported by the distortion interaction analysis in Supplementary Fig. 5b. By using the (R)-SPINOL-C1 catalyst, the Michael-addition step mainly determined the reaction rate and led to the more stable INT3-C-SR intermediate readily for proton transfer step forming Pro-SRS. From Supplementary Fig. 5b, the interaction energy of $(R)-\mathbf{C l}$ catalyst and substrate dominates the energy difference of TS2-C-SR and TS2-C- $R$ S probably because of the steric repulsion between 3,3'-substitutent of the $\mathbf{C 1}$ catalyst and the ethyl group of $\mathbf{2 a}$, indicating the rigid conformation of SPINOL-C1 catalyst may encounter non-negligible interactions between catalyst and substrate, compared with the relatively flexible conformation of H8-BINOL-B2 catalyst. The stereoisomerization of enol intermediate INT $\mathbf{3}$ via low barrier tautomerization and single bond rotation was omitted for clarity. Finally, our calculation predicted the products with $95 \%$ ee, $17: 1$ dr (exp. 91\% ee, 20:1 dr) and 98\% ee, 15:1 dr (exp. 97\% ee, 12:1 dr) under $(S)$-B2 and $(R)-\mathbf{C 1}$ catalysis, respectively, which are in agreement with the experimental results.

For the origin of chirality control in the proton transfer step for construction of the allenic axial chirality, we found two types of models among our 20 calculated TSs structures (see Supplementary Table 3). In Fig. 5a, stacking-type model tends to form $S$-axial chirality configuration TSs, where the substitutions of the intermediate in transition state TS3 have strong intramolecular interaction (i.e., $\pi-\pi$ interaction supported by the NCIs plots ${ }^{67}$ of Fig. 5c) and the resonance stabilization between the phenyl group $\left(\mathrm{R}^{1}\right)$ and the allenic moiety in 1a (see Supplementary Fig. 6 for details). In contrast, stagger-type model prefer $R$-axial chirality configuration TS with emphasizing the intermolecular interactions of CPA catalyst and substrates (for the distortion-interaction analysis and NCIs plots of TSs see Supplementary Figs. 6 and 7). Due to the relatively rigid conformation of $(R)$-SPINOL-C1 catalyst, stacking-type model is favored for the TSs of proton transfer step to fit the cavity of catalyst with certain entropy loss, leading to $S$-axial chirality configuration. That is consistent with less steric repulsion between catalyst and substrate in the stackingtype model, which is the dominant effect by Energy Decomposition Analysis (EDA) calculations ${ }^{68}$ as shown in Fig. 5b. The (S)-H8BINOL-B2 catalyst with slightly flexible conformation are more likely to adopt stagger-type mode forming $R$-axial chirality configuration, which is mainly stabilized by the dispersion effect by EDA calculation. As shown in NCIs plots in Fig. 5c, this dispersion effect between the methyl group of catalyst B2 and substrate in TS3-B-SRR can well rationalize the catalyst 
a Control experiment:

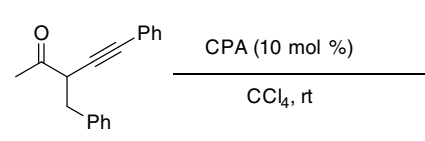

$( \pm)-5 a$<smiles>CC(=O)C(=Cc1ccccc1)c1ccccc1</smiles>

$6 a$

with CPA (S)-B2, 92\%, 80\% ee with CPA $(R)-\mathbf{C} 1,80 \%,-48 \%$ ee

b Initially proposed mechanism:

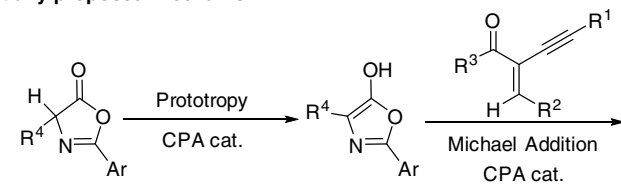

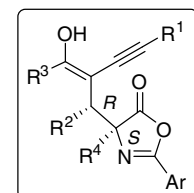

Enol intermediate INT A

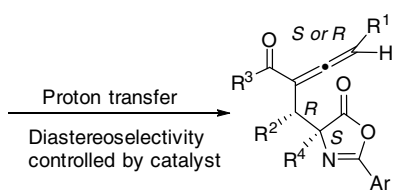

Desired product

C Activation modes (Prototropy and Michael-Addition):

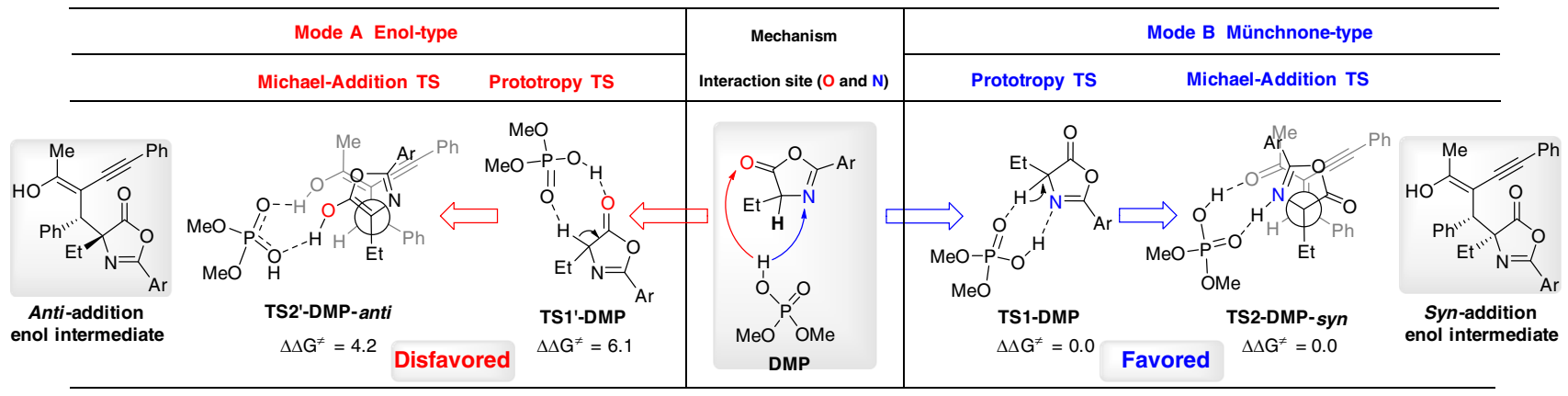

d Energy profiles of Michael-Addition and Proton transfer with chiral catalysts:

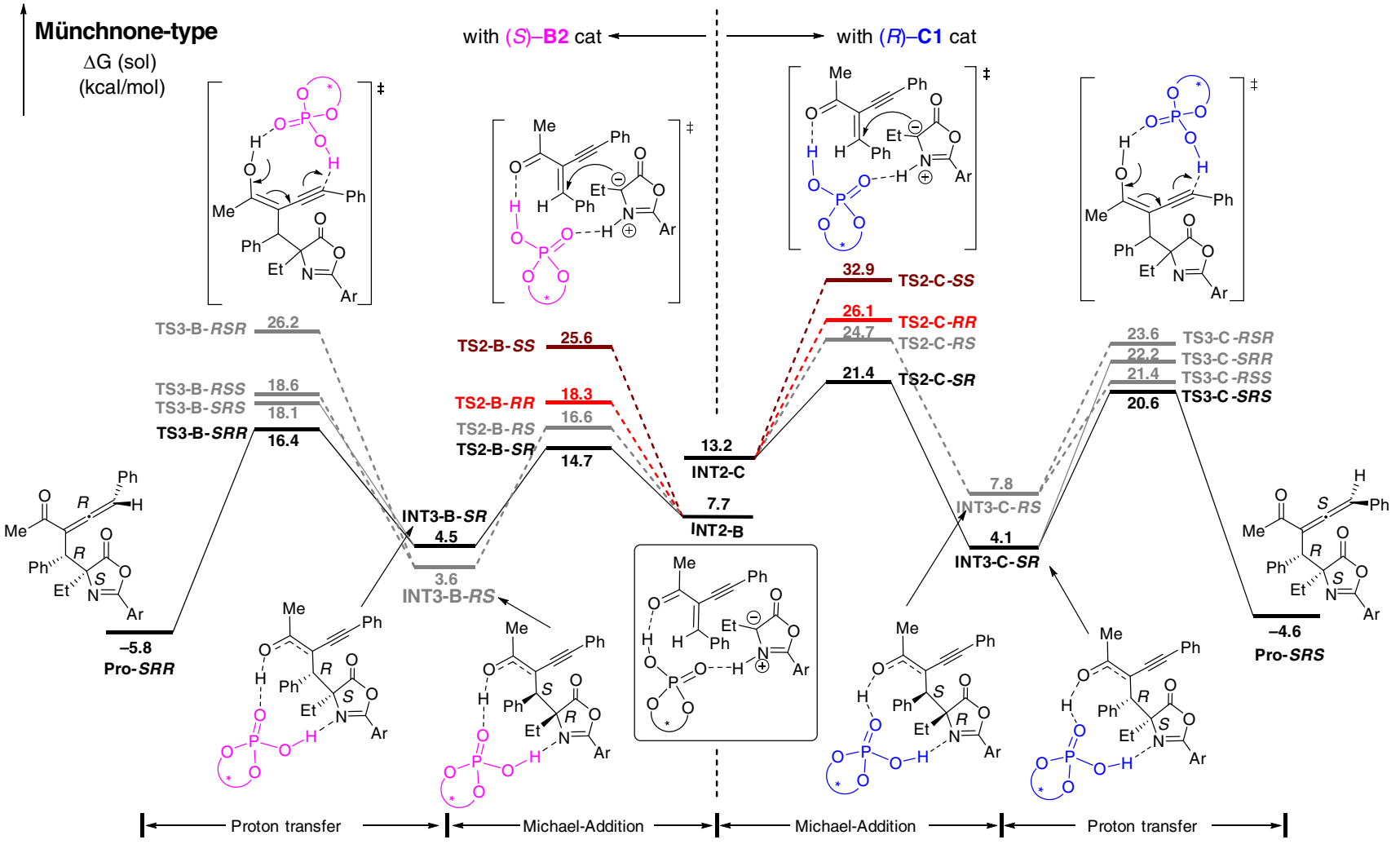

Fig. 4 Mechanistic studies. a Control experiments. b Initially proposed enol-type mode mechanism. c Comparison of the enol-type and Münchnone-type activation modes via calculation. d Energy profiles of Michael-Addition and proton transfer with CPA catalysts via DFT calculations. (The energy shown in $\mathrm{kcal} / \mathrm{mol}, \mathrm{Ar}=3,5$-dimethoxyphenyl). 
A Interaction modes between CPA catalyst and enol intermediat for proton transfer

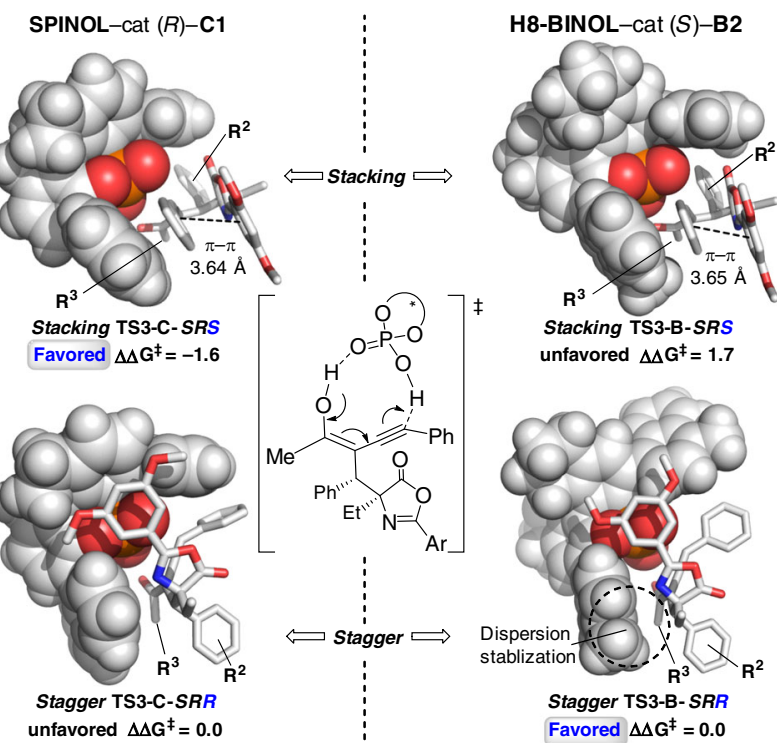

D Origins of catalyst and substrate effects on stereoselectivity for proton transfer SPINOL-Cat $(R)-\mathrm{C} 1$ $\Delta \Delta \mathrm{E}^{\ddagger}=-6.7$

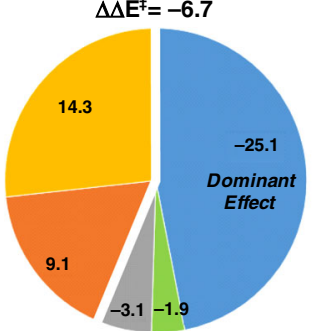

$\Delta \Delta \mathrm{E}^{\ddagger}=\Delta \Delta \mathrm{E}^{\ddagger}$ stacking-TS $-\Delta \Delta \mathrm{E}^{\ddagger}$ stagger-TS

C Noncovalent interaction analysis of transition state for proton transfer

SPINOL-Cat $(R)-\mathrm{C} 1$

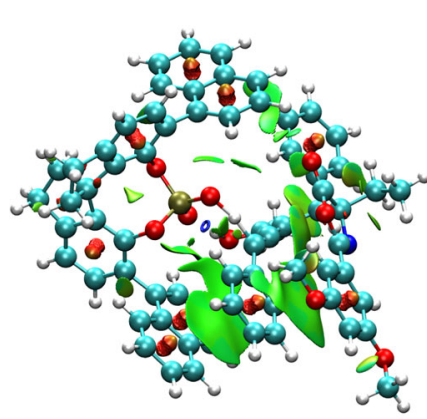

Stacking TS3-C-SRS

Favored

d Transition states of proton transfer catalyzed by two CPAs SPINOL-Cat $(R)-\mathrm{C} 1$

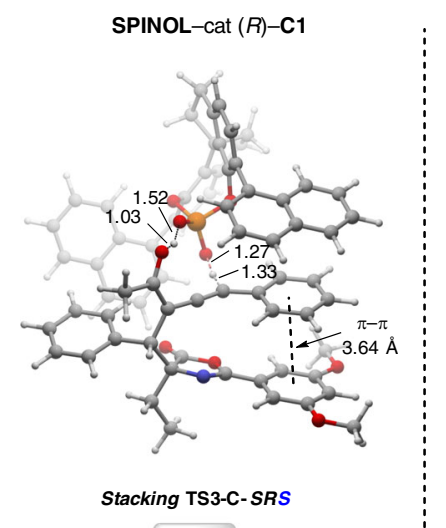

Stacking TS3-C-SRS

Favored
H8-BINOL-cat (S)-B2

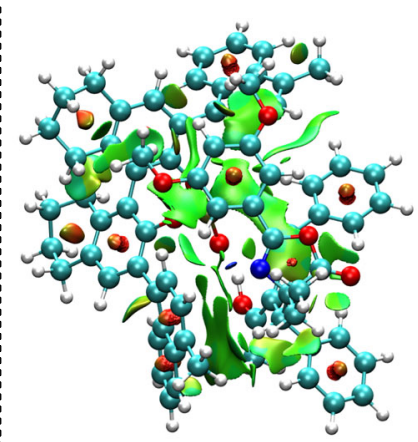

Stagger TS3-B-SRR

Favored
H8-BINOL-cat (S)-B2

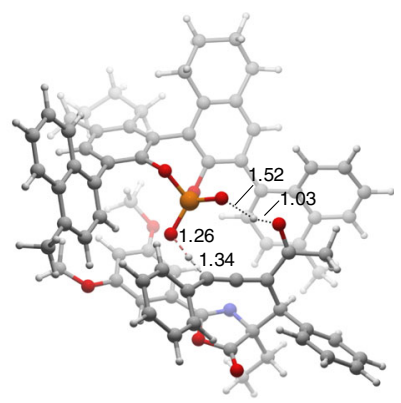

Stagger TS3-B-SRR

Favored

Fig. 5 Computational studies on origin of diastereoselectivity. Comparison two types of interaction modes between CPA $(R)-\mathbf{C 1} /(S)-\mathbf{B 2}$ and substrates. a Space-filling model of stacking-TS versus stagger-TS for proton transfer. $\mathbf{b}$ Energy Decomposition Analysis (EDA) of transition states for proton transfer at B3LYP-D3/TZ2P level of theory by using ETS-NOCV in ADF. The relative energy $\left(\Delta \Delta \mathrm{E}^{+}\right)$is the sum of $\Delta \Delta \mathrm{E}_{0}+$ and $\left(-\mathrm{T} \Delta \Delta \mathrm{S}^{+}\right)$, where the entropy term is from Gaussian calculations. For the energy decomposition analysis equation follows: $\Delta \Delta \mathrm{E}_{0}^{\dagger}=\Delta \Delta \mathrm{E}_{\text {steric }}+\Delta \Delta \mathrm{E}_{\text {elstat }}+\Delta \Delta \mathrm{E}_{\text {orbital }}+\Delta \Delta \mathrm{E}_{\text {disper. The }} \Delta \Delta \mathrm{E}^{\ddagger}$ is calculated from the electronic energy difference between stacking-type TS and stagger-type $\mathrm{TS}\left(\Delta \Delta \mathrm{E}^{+}=\Delta \mathrm{E}_{\text {stacking-Ts }}-\Delta \mathrm{E}_{\text {stagger-Ts }}\right)$. Each energy component $\left(\Delta \Delta \mathrm{E}_{\text {steric }}\right.$ $\Delta \Delta \mathrm{E}_{\text {elstat, }} \Delta \Delta \mathrm{E}_{\text {orbital, }}$ and $\Delta \Delta \mathrm{E}_{\text {disper }}$ ) is calculated in the same fashion. Positive $\Delta \Delta \mathrm{E}$ values indicate corresponding interactions promote stagger-type, and $R$-axial chirality TS is more favored. In contrast, negative $\Delta \Delta \mathrm{E}$ values indicate $\mathrm{S}$-axial chirality TS with stacking-type is more stable; $\mathrm{E}_{\text {steric }}$ is the positive term as the steric repulsion, and $\mathrm{E}_{\text {disper }}$ is the negative term as the dispersion stabilization. c Noncovalent Interactions ( $\mathrm{NCls}$ ) analysis of transition state for proton transfer (green, dispersion effect; red, steric effect). The gradient isosurfaces ( $s=0.3$ a.u.) are colored on an BGR scale according to sign $\left(\lambda_{2}\right) \rho$ over the range -0.01 to 0.01 au. d Detailed structural information of proton transfer transition states catalyzed by two CPAs. The energies shown in $\mathrm{kcal} / \mathrm{mol}$.

Table 2 Calculated free energies of activation for proton transfer transition states for substrates with different $R^{2} / R^{3}$ substituents.

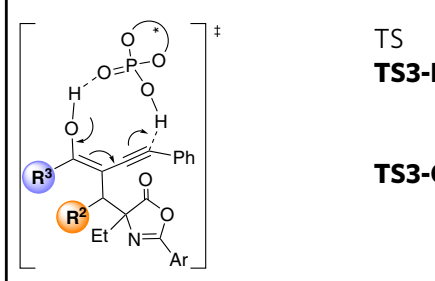

$\begin{array}{llll}\text { TS } & \mathbf{R}^{2} & \mathbf{R}^{3} & \text { exp }{ }^{\text {ad }} \text { d.r. } \\ \text { TS3-B } & \mathrm{Ph} & \mathrm{Me} & 20: 1 \\ & \mathrm{Cy} & \mathrm{Me} & 4: 1 \\ & \mathrm{Ph} & \mathrm{nPr} & 23: 1 \\ \text { TS3-C } & \mathrm{Ph} & \mathrm{Me} & 12: 1 \\ & \mathrm{Cy} & \mathrm{Me} & 13: 1\end{array}$

$\exp ^{\mathrm{b}} \Delta \Delta \mathrm{G}$
1.8
0.8
1.9
1.5
1.5

calc $^{\mathrm{b}} \Delta \Delta \mathrm{G}$

1.7

1.1

3.0

1.6

1.8

aln B2 catalysis, the diastereoselective ratio is $\mathbf{3}$ (major): $\mathbf{4}$ (minor), and in $\mathbf{C 1}$ catalysis, the diastereoselective ratio is $\mathbf{4}$ (major): $\mathbf{3}$ (minor).

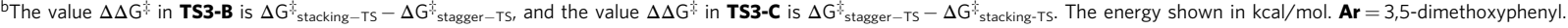

B2 featuring a 1-(4-Me-naphthyl) substitution (over just 1-naphthyl in catalyst B1) could improve the diastereoselectivity significantly $(2.7: 1$ to $10: 1$, see Table 1$)$. For this catalyst, the $\Delta \Delta \mathrm{E}_{\text {orbital, }}$ a high proportion for energy, stabilized for the unfavorable TS3-B-SRS, which can be rationalized by the dihedral angle $\angle \mathrm{C} 1-\mathrm{C} 2-\mathrm{C} 3-\mathrm{H} 1$ of forming hydrogen bond and allene as shown in Supplementary Fig. 8. The dihedral angle in TS3-B-SRS is $85.0^{\circ}$, which is more close to perpendicular than that in TS3-B-SRR 
a

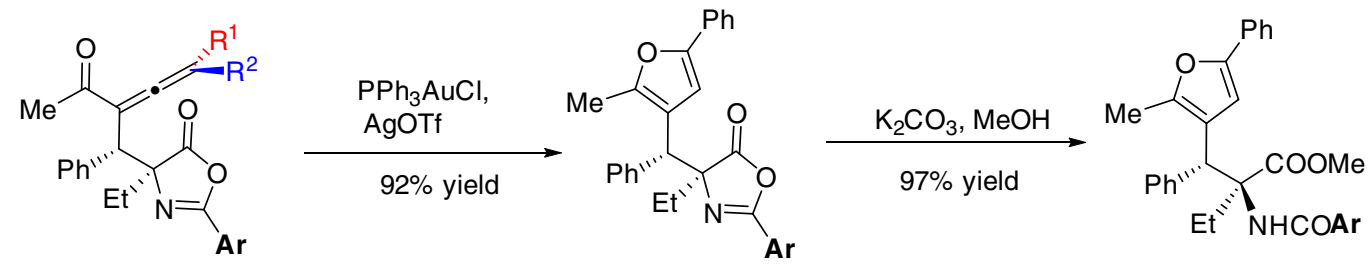

3a, $R^{1}=P h, R^{2}=H, 91 \%$ ee

7a $97 \%$ ee (from 4a)

8a $98 \%$ ee

4a, $R^{1}=H, R^{2}=P h, 97 \%$ ee

b<smiles>CC[C@@H](c1ccccc1)C(C(=Cc1ccccc1)C(C)=O)c1ccccc1</smiles>

3a $91 \%$ ee<smiles>CCC1(NC(=O)[Ge])C(=O)OC(C)C(=C=Cc2ccccc2)[C@@H]1c1ccccc1</smiles>

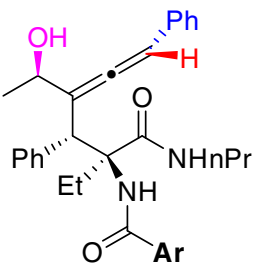<smiles>[AlH2]</smiles>

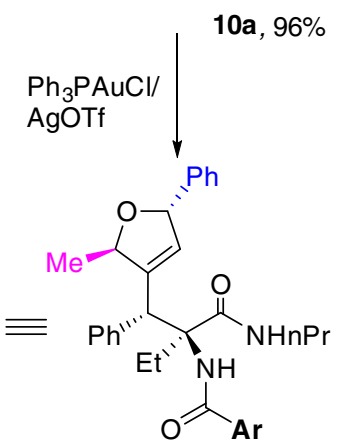

x-ray

$12 a, 68 \%, 91 \%$ ee

$11 a, 98 \%, 92 \%$ ee

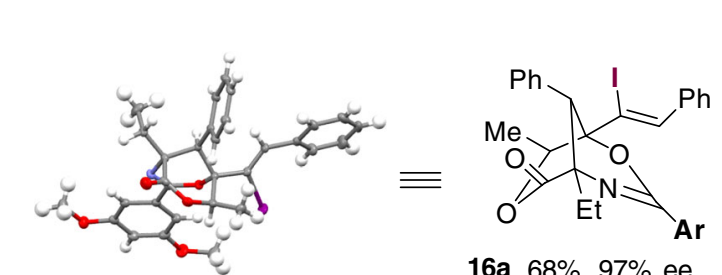

$16 a, 68 \%, 97 \%$ ee

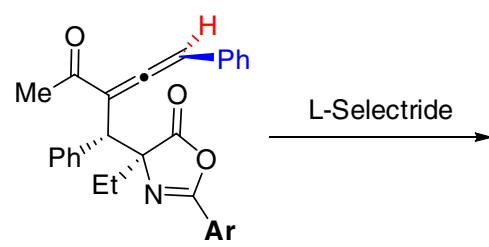

4a $97 \%$ ee

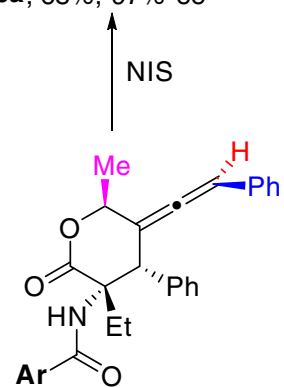

13a, $76 \%, 97 \%$ ee<smiles>CCCNC(=O)C(N)(C(=O)NCC)C(c1ccccc1)c1cc(-c2ccccc2)oc1C</smiles>

15a, $83 \%, 97 \%$ ee o

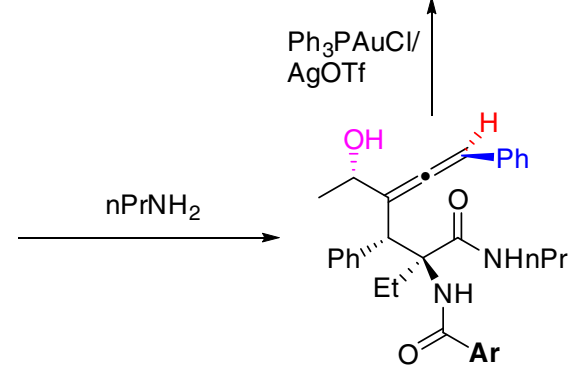

$14 a, 66 \%$

Fig. 6 Derivatizations of the chiral allene products. a Synthesis of chiral furan derivatives. $\mathbf{b}$ Derivatizations of the chiral allene products for chemodiversity-oriented and stereo-diversity-oriented synthesis. $\mathbf{A r}=3,5$-dimethoxyphenyl.

with $80.2^{\circ}$. However, this orbital interaction cannot overcome the steric and dispersion effect that favor TS3-B-SRR as a stagger-form in the overall relative energy. The calculated results demonstrate the substrates may dynamically orientate their conformations to interact favorably with various cavities of catalysts under the promotion of inter-/intramolecular interactions.
To confirm validity of the stereo-models in the proton transfer step, we performed additional DFT calculations for understanding substituent effects of $\mathrm{R}^{2}$ and $\mathrm{R}^{3}$ group in $\mathbf{1}$ as shown in Table 2 . The calculated diastereoselectivities are in well agreement with the trend of our experimental substituent effects. In B2 catalysis, dispersion effects dominate in the stereo-control. When 
the cyclohexyl group (Cy) at the $\mathrm{R}^{2}$ of $\mathbf{1}$ was introduced and TS3B-SRS-Cy would be stabilized due to the $\mathrm{CH}-\pi$ dispersion effect between cyclohexyl and 4-Me-naphthyl group, which therefore decrease the energy gap for diastereoselectivity. And, $n$-propyl group $(n P r)$ at $R^{3}$ in $\mathbf{1}$ also emphasize the dispersion effect with 4-Me-naphthyl group of $\mathbf{B} 2$ catalyst, which mainly stabilize the transition state TS3-B-SRR-nPr and thus increase the diastereoselectivity. In contrast, the relatively rigid conformation and small cavity for $\mathbf{C l}$ catalysis make steric repulsions become important. Introducing the relatively larger cyclohexyl group to substrates would increase energy barriers for both the stacking-forms and stagger-forms of TS3-C, resulting slightly increased energy gap for the diastereoselectivity (see Supplementary Table 5 for details). While switching the $\mathrm{R}^{3}$ group to $n$-propyl under $\mathbf{C} \mathbf{1}$ catalyst led to very low reactivity by our experiment (see Supplementary Fig. 1), and thus further discussions on the diastereoselectivity is trivial.

Derivatizations of the chiral allene products for diversityoriented synthesis. To demonstrate the applicability of these reactions, we devoted our efforts to exploring the derivatizations of the chiral allene products (Fig. 6). Rearrangement of chiral allene 4a into tri-substituted furan $7 \mathbf{a}$ was performed under gold (I) catalysis, providing the product in $92 \%$ yield. Further alcoholysis of the oxazolone moiety in $7 \mathbf{a}$ provided the $\beta, \beta$-di-aryl substituted amino acid derivative $\mathbf{8 a}$, which is a type of important pharmacophore in a series of bioactive small molecules. Analogously, gold(I)-catalyzed rearrangement of $\mathbf{3 a}$ afforded the furan derivative $7 \mathbf{a}$ with the same bias on a chiral stationary phase, thus confirming the absolute configuration of 3a (Fig. 6a). To achieve diversity-oriented synthesis (DOS) ${ }^{69}$ from these chiral allene products, diastereoselective reduction of $\mathbf{3 a}$ with L-Selectride followed by in-situ intramolecular transesterification provided the lactone 9a $(>25: 1 \mathrm{dr})^{70}$. Aminolysis of lactone $7 \mathbf{a}$ with $n \mathrm{PrNH}_{2}$ yielded the allenic alcohol 10a, which was stereospecifically cyclized in the presence of gold(I) catalyst to give the 2,5-dihydrofuran derivatives 11a, whose absolute structure was confirmed by X-ray crystallography. Analogously, treatment of chiral allene 4a with the same three-steps procedure readily provided the diastereomeric chiral 2,5-dihydrofuran 15a (Fig. 6b). Moreover, derivatizations of the chiral allene products were not limited to stereochemical diversities, but could be extended to skeletal diversities. Electrophilic iodocyclization of lactone $\mathbf{9 a}$ in the presence of NIS provided the tricyclic product 12a, in which the phenyl group reacted as the nucleophile. On the other hand, treatment of the diastereomeric lactone 13a with the same electrophilic iodination conditions generated the bridged bicyclic product 16a, in which the amide group reacted as the nucleophile; the structures of these cyclization products were all well confirmed by X-Ray crystallography.

\section{Discussion}

In summary, we have disclosed an enantioselective and diastereodivergent synthesis of trisubstituted allenes via asymmetric conjugate additions of oxazolones to activated 1,3-enynes under chiral phosphoric acid catalysis, where the axial stereogenicity of the chiral allene products could be well modulated by modifications of the CPA catalysts. The origin of allenic axial diastereodivergence is well elucidated by the stacking-form and staggerform in transition states from DFT calculations, in which a Münchnone-type model on activation of oxazolones under Brønsted acid catalysis has also been demonstrated with high model dependency of diastereoselectivities. The stereo-specific and chemo-specific transformations of the diastereomeric chiral allenes into more complex stereoisomers and skeletal isomers demonstrate the value of these reactions in organic synthesis, especially in the field of DOS.

\section{Methods}

General procedure for asymmetric synthesis of chiral products $\mathbf{3}$ and $\mathbf{4}$. To a dried $3 \mathrm{ml}$ vial was added $\mathbf{1}(0.15 \mathrm{mmol}), 2(0.1 \mathrm{mmol})$, CPA catalyst $(0.01 \mathrm{mmol})$, and activated $3 \AA$ molecular sieves $\left(100 \mathrm{mg}\right.$ ). The vial was purged with $\mathrm{N}_{2}$ for 3 times and then followed by adding $\mathrm{CCl}_{4}(0.5 \mathrm{~mL})$. After stirring for $24 \mathrm{~h}$ at room temperature, the reaction mixture was quenched by adding $\mathrm{K}_{2} \mathrm{CO}_{3}$. After filtration, the filtrate was concentrated under vacuum to give a residue, which was purified by flash column chromatography to give the allene products 3 or 4 . (Toluene is an alternative choice of solvent used in these reactions, if the usage of $\mathrm{CCl}_{4}$ is restricted). Full experimental details and characterization of new compounds can be found in the Supplementary Information.

\section{Data availability}

The authors declare that the data supporting the findings of this study are available within the article and Supplementary Information file, or from the corresponding author upon reasonable request. The X-ray crystallographic coordinates for structures reported in this study have been deposited at the Cambridge Crystallographic Data Centre (CCDC), under deposition numbers CCDC 1971171, 1971946, 1971947, 1971365, and 1971366. These data can be obtained free of charge from The Cambridge Crystallographic Data Centre via www.ccdc.cam.ac.uk/data_request/cif.

Received: 11 May 2020; Accepted: 5 October 2020;

Published online: 02 November 2020

\section{References}

1. Rivera-Fuentes, P. \& Diederich, F. Allenes in molecular materials. Angew. Chem. Int. Ed. 51, 2818-2828 (2012).

2. Hoffmann-Röder, A. \& Krause, N. Synthesis and properties of allenic natural products and pharmaceuticals. Angew. Chem. Int. Ed. 43, 1196-1216 (2004).

3. Yu, S. \& Ma, S. Allenes in catalytic asymmetric synthesis and natural product syntheses. Angew. Chem. Int. Ed. 51, 3074-3112 (2012).

4. Ogasawara, M. Catalytic enantioselective synthesis of axially chiral allenes. Tetrahedron 20, 259-271 (2009).

5. Ye, J. \& Ma, S. Conquering three-carbon axial chirality of allenes. Org. Chem. Front. 1, 1210-1224 (2014)

6. Chu, W.-D., Zhang, Y. \& Wang, J. Recent advances in catalytic asymmetric synthesis of allenes. Catal. Sci. Technol. 7, 4570-4579 (2017).

7. Han, J. W., Tokunaga, N. \& Hayashi, T. Palladium-catalyzed asymmetric hydrosilylation of 4-substituted 1-buten-3-ynes. catalytic asymmetric synthesis of axially chiral allenylsilanes. J. Am. Chem. Soc. 123, 12915-12916 (2001).

8. Hayashi, T., Tokunaga, N. \& Inoue, K. Rhodium-catalyzed asymmetric 1,6addition of aryltitanates to enynones giving axially chiral allenes. Org. Lett. 6, 305-307 (2004).

9. Nishimura, T., Makino, H., Nagaosa, M. \& Hayashi, T. Rhodium-catalyzed enantioselective 1,6-addition of arylboronic acids to enynamides: asymmetric synthesis of axially chiral allenylsilanes. J. Am. Chem. Soc. 132, 12865-12867 (2010).

10. Wang, M. et al. Synthesis of highly substituted racemic and enantioenriched allenylsilanes via copper-catalyzed hydrosilylation of (Z)-2-alken-4-ynoates with silylboronate. J. Am. Chem. Soc. 137, 14830-14833 (2015).

11. Yao, Q. et al. Efficient synthesis of chiral trisubstituted 1,2-allenyl ketones by catalytic asymmetric conjugate addition of malonic esters to enynes. Angew. Chem. Int. Ed. 55, 1859-1863 (2016).

12. Huang, Y., del Pozo, J., Torker, S. \& Hoveyda, A. H. Enantioselective synthesis of trisubstituted allenyl-B(pin) compounds by phosphine-Cu-catalyzed 1,3enyne hydroboration. insights regarding stereochemical integrity of Cu-allenyl intermediates. J. Am. Chem. Soc. 140, 2643-2655 (2018).

13. Adamson, N. J., Jeddi, H. \& Malcolmson, S. J. Preparation of chiral allenes through Pd-catalyzed intermolecular hydroamination of conjugated enynes: enantioselective synthesis enabled by catalyst design. J. Am. Chem. Soc. 141, 8574-8583 (2019)

14. Bayeh-Romero, L. \& Buchwald, S. L. Copper hydride catalyzed enantioselective synthesis of axially chiral 1,3-disubstituted allenes. J. Am. Chem. Soc. 141, 13788-13794 (2019).

15. Zhang, W. et al. Enantioselective bromolactonization of conjugated (Z)enynes. J. Am. Chem. Soc. 132, 3664-3665 (2010).

16. Qian, H., Yu, X., Zhang, J. \& Sun, J. Organocatalytic enantioselective synthesis of 2,3-allenoates by intermolecular addition of nitroalkanes to activated enynes. J. Am. Chem. Soc. 135, 18020-18023 (2013).

17. Poulsen, P. H. et al. Organocatalytic formation of chiral trisubstituted allenes and chiral furan derivatives. Angew. Chem. Int. Ed. 57, 10661-10665 (2018). 
18. Ma, Z.-G. et al. Asymmetric organocatalytic synthesis of 2,3-allenamides from hydrogen-bond-stabilized enynamides. Org. Lett. 21, 2468-2472 (2019).

19. Yu, X., Ren, H., Xiao, Y. \& Zhang, J. Efficient assembly of allenes, 1,3-dienes, and $4 \mathrm{H}$-pyrans by catalytic regioselective nucleophilic addition to electrondeficient 1,3-conjugated enynes. Chem. Eur. J. 14, 8481-8485 (2008).

20. Deska, J., del Pozo Ochoa, C. \& Bäckvall, J.-E. Chemoenzymatic dynamic kinetic resolution of axially chiral allenes. Chem. Eur. J. 16, 4447-4451 (2010).

21. Hashimoto, T., Sakata, K., Tamakuni, F., Dutton, M. J. \& Maruoka, K. Phasetransfer-catalysed asymmetric synthesis of tetrasubstituted allenes. Nat. Chem. 5, 240 (2013).

22. Mbofana, C. T. \& Miller, S. J. Diastereo- and enantioselective addition of anilide-functionalized allenoates to $\mathrm{N}$-acylimines catalyzed by a pyridylalanine-based peptide. J. Am. Chem. Soc. 136, 3285-3292 (2014)

23. Liu, H., Leow, D., Huang, K.-W. \& Tan, C.-H. Enantioselective synthesis of chiral allenoates by guanidine-catalyzed isomerization of 3-alkynoates. J. Am. Chem. Soc. 131, 7212-7213 (2009).

24. Wang, Y., Zhang, W. \& Ma, S. A room-temperature catalytic asymmetric synthesis of allenes with ECNU-Phos. J. Am. Chem. Soc. 135, 11517-11520 (2013).

25. Liu, Y. et al. Nickel(II)-catalyzed asymmetric propargyl and allyl claisen rearrangements to allenyl- and allyl-substituted $\beta$-ketoesters. Angew. Chem. Int. Ed. 53, 11579-11582 (2014)

26. Tang, Y. et al. Direct synthesis of chiral allenoates from the asymmetric C-H insertion of $\alpha$-diazoesters into terminal alkynes. Angew. Chem. Int. Ed. 54, 9512-9516 (2015).

27. Chu, W.-D. et al. Enantioselective synthesis of trisubstituted allenes via $\mathrm{Cu}(\mathrm{I})$ catalyzed coupling of diazoalkanes with terminal alkynes. J. Am. Chem. Soc 138, 14558-14561 (2016).

28. Tang, Y. et al. Asymmetric three-component reaction for the synthesis of tetrasubstituted allenoates via allenoate-copper intermediates. Chem $\mathbf{4}$, 1658-1672 (2018).

29. Crouch, I. T., Neff, R. K. \& Frantz, D. E. Pd-catalyzed asymmetric $\beta$-hydride elimination en route to chiral allenes. J. Am. Chem. Soc. 135, 4970-4973 (2013).

30. Qian, D., Wu, L., Lin, Z. \& Sun, J. Organocatalytic synthesis of chiral tetrasubstituted allenes from racemic propargylic alcohols. Nat. Commun. 8, 567 (2017).

31. Zheng, W.-F. et al. Tetrasubstituted allenes via the palladium-catalysed kinetic resolution of propargylic alcohols using a supporting ligand. Nat. Catal. 2, 997-1005 (2019).

32. Jacobsen, E. N., Pfaltz, A. \& Yamamoto, H. Comprehensive Asymmetric Catalysis. Vol. I-III (Springer, 1999).

33. Bihani, M. \& Zhao, J. C. G. Advances in asymmetric diastereodivergent catalysis. Adv. Synth. Catal. 359, 534-575 (2017).

34. Lin, L. \& Feng, X. Catalytic strategies for diastereodivergent synthesis. Chem. Eur. J. 23, 6464-6482 (2017).

35. Krautwald, S. \& Carreira, E. M. Stereodivergence in asymmetric catalysis. J. Am. Chem. Soc. 139, 5627-5639 (2017).

36. Li, X. et al. Diastereodivergent organocatalytic asymmetric vinylogous Michael reactions. Nat. Commun. 5, 4479 (2014)

37. Zhan, G. et al. Catalyst-controlled switch in chemo- and diastereoselectivities: annulations of Morita-Baylis-Hillman carbonates from Isatins. Angew. Chem. Int. Ed. 55, 2147-2151 (2016).

38. Dai, J. et al. Chiral primary amine catalysis for asymmetric mannich reactions of aldehydes with ketimines: stereoselectivity and reactivity. Angew. Chem. Int. Ed. 56, 12697-12701 (2017).

39. Lv, J., Zhang, L., Luo, S. \& Cheng, J. P. Switchable diastereoselectivity in enantioselective $[4+2]$ cycloadditions with simple olefins by asymmetric binary acid catalysis. Angew. Chem. Int. Ed. 52, 9786-9790 (2013).

40. Luparia, M. et al. Catalytic asymmetric diastereodivergent deracemization. Angew. Chem. Int. Ed. 50, 12631-12635 (2011).

41. Audisio, D., Luparia, M., Oliveira, M. T., Klütt, D. \& Maulide, N. Diastereodivergent de-epimerization in catalytic asymmetric allylic alkylation. Angew. Chem. Int. Ed. 51, 7314-7317 (2012).

42. Tian, X. et al. Diastereodivergent asymmetric Sulfa-Michael additions of a-branched enones using a single chiral organic catalyst. J. Am. Chem. Soc. 133, 17934-17941 (2011).

43. McInturff, E. L., Yamaguchi, E. \& Krische, M. J. Chiral-anion-dependent inversion of diastereo- and enantioselectivity in carbonyl crotylation via ruthenium-catalyzed butadiene hydrohydroxyalkylation. J. Am. Chem. Soc. 134, 20628-20631 (2012).

44. Krautwald, S., Sarlah, D., Schafroth, M. A. \& Carreira, E. M. Enantio- and diastereodivergent dual catalysis: $\alpha$-allylation of branched aldehydes. Science 340, 1065 (2013).

45. Huo, X., He, R., Zhang, X. \& Zhang, W. An Ir/Zn dual catalysis for enantioand diastereodivergent $\alpha$-allylation of $\alpha$-hydroxyketones. J. Am. Chem. Soc. 138, 11093-11096 (2016).
46. Cruz, F. A. \& Dong, V. M. Stereodivergent coupling of aldehydes and alkynes via synergistic catalysis using $\mathrm{Rh}$ and Jacobsen's Amine. J. Am. Chem. Soc. 139, 1029-1032 (2017).

47. Jiang, X., Beiger, J. J. \& Hartwig, J. F. Stereodivergent allylic substitutions with aryl acetic acid esters by synergistic iridium and lewis base catalysis. J. Am. Chem. Soc. 139, 87-90 (2017).

48. Wei, L., Zhu, Q., Xu, S.-M., Chang, X. \& Wang, C.-J. Stereodivergent synthesis of $\alpha, \alpha$-disubstituted $\alpha$-amino acids via synergistic $\mathrm{Cu} / \mathrm{Ir}$ catalysis. J. Am. Chem. Soc. 140, 1508-1513 (2018).

49. Zhang, Q. et al. Stereodivergent coupling of 1,3-dienes with aldimine esters enabled by synergistic Pd and Cu catalysis. J. Am. Chem. Soc. 141, 14554-14559 (2019).

50. Singha, S., Serrano, E., Mondal, S., Daniliuc, C. G. \& Glorius, F. Diastereodivergent synthesis of enantioenriched $\alpha, \beta$-disubstituted $\gamma$-butyrolactones via cooperative $\mathrm{N}$-heterocyclic carbene and $\mathrm{Ir}$ catalysis. Nat. Catal. 3, 48-54 (2020).

51. Huang, Y., Walji, A. M., Larsen, C. H. \& MacMillan, D. W. C. Enantioselective organo-cascade catalysis. J. Am. Chem. Soc. 127, 15051-15053 (2005).

52. Huang, H., Konda, S. \& Zhao, J. C.-G. Diastereodivergent catalysis using modularly designed organocatalysts: synthesis of both cis- and trans-fused pyrano[2,3-b]pyrans. Angew. Chem. Int. Ed. 55, 2213-2216 (2016).

53. Lotter, D., Castrogiovanni, A., Neuburger, M. \& Sparr, C. Catalyst-controlled stereodivergent synthesis of atropisomeric multiaxis systems. ACS Cent. Sci. 4, 656-660 (2018).

54. Kwon, Y., Chinn, A. J., Kim, B. \& Miller, S. J. Divergent control of point and axial stereogenicity: catalytic enantioselective $\mathrm{C}-\mathrm{N}$ bond-forming crosscoupling and catalyst-controlled atroposelective cyclodehydration. Angew. Chem. Int. Ed. 57, 6251-6255 (2018).

55. Yan, X.-X. et al. Highly diastereoselective switchable enantioselective mannich reaction of glycine derivatives with imines. J. Am. Chem. Soc. 130 14362-14363 (2008)

56. Uraguchi, D., Yoshioka, K. \& Ooi, T. Complete diastereodivergence in asymmetric 1,6-addition reactions enabled by minimal modification of a chiral catalyst. Nat. Commun. 8, 14793 (2017)

57. Jiang, J., Qing, J. \& Gong, L.-Z. Asymmetric synthesis of 3-amino- $\delta$-lactams and benzo[a]quinolizidines by catalytic cyclization reactions involving azlactones. Chem. Eur. J. 15, 7031-7034 (2009).

58. Terada, M., Tanaka, H. \& Sorimachi, K. Enantioselective direct aldol-type reaction of azlactone via protonation of vinyl ethers by a chiral brønsted acid catalyst. J. Am. Chem. Soc. 131, 3430-3431 (2009).

59. Zhang, Z. et al. Chiral phosphoric acid catalyzed enantioselective 1,3-dipolar cycloaddition reaction of azlactones. Chem. Commun. 52, 1377-1380 (2016).

60. Kanomata, K. et al. Mechanism and origin of stereoselectivity in chiral phosphoric acid-catalyzed aldol-type reactions of azlactones with vinyl ethers. Chem. Eur. J. 26, 3364-3372 (2020).

61. $\mathrm{Xu}, \mathrm{B}$. et al. Insertion reaction cooperatively catalyzed by rhodium and chiral spiro phosphoric acids. Angew. Chem. Int. Ed. 50, 11483-11486 (2011).

62. $\mathrm{Xu}, \mathrm{B}$. et al. Highly enantioselective $\mathrm{S}-\mathrm{H}$ bond insertion cooperatively catalyzed by dirhodium complexes and chiral spiro phosphoric acids. Chem. Sci. 5, 1442-1448 (2014).

63. Lam, Y.-h., Grayson, M. N., Holland, M. C., Simon, A. \& Houk, K. N. Theory and modeling of asymmetric catalytic reactions. Acc. Chem. Res. 49, 750-762 (2016).

64. Sunoj, R. B. Transition state models for understanding the origin of chira induction in asymmetric catalysis. Acc. Chem. Res. 49, 1019-1028 (2016).

65. Peng, Q., Duarte, F. \& Paton, R. S. Computing organic stereoselectivity-from concepts to quantitative calculations and predictions. Chem. Soc. Rev. 45, 6093-6107 (2016).

66. Peddibhotla, S. \& Tepe, J. J. Stereoselective synthesis of highly substituted $\Delta$-Pyrrolines: exo-selective 1,3-dipolar cycloaddition reactions with azlactones. J. Am. Chem. Soc. 126, 12776-12777 (2004).

67. Johnson, E. R. et al. Revealing noncovalent interactions. J. Am. Chem. Soc 132, 6498-6506 (2010).

68. Qi, X., Kohler, D. G., Hull, K. L. \& Liu, P. Energy decomposition analyses reveal the origins of catalyst and nucleophile effects on regioselectivity in nucleopalladation of alkenes. J. Am. Chem. Soc. 141, 11892-11904 (2019).

69. Schreiber, S. L. Target-oriented and diversity-oriented organic synthesis in drug discovery. Science 287, 1964 (2000).

70. Marshall, J. A. \& Tang, Y. Allene-directed diastereoselection. Additions to chiral allenyl aldehydes and ketones. J. Org. Chem. 58, 3233-3234 (1993).

\section{Acknowledgements}

This work is dedicated to the 70th anniversary of Shanghai Institute of Organic Chemistry and 100th anniversary of the School of Chemistry and Chemical Engineering, Nanjing University. We gratefully acknowledge NSFC (Grant Nos. 21702138, 21890722, 
21702109, 11811530637, 21950410519), the Natural Science Foundation of Tianjin Municipality (18JCYBJC21400, 19JCJQJC62300), Tianjin Research Innovation Project for Postgraduate Students (2019YJSB081), ShanghaiTech University start-up funding, and the Fundamental Research Funds for Central Universities [Nankai University (Nos. 63201043, 63203002)] for financial support. The authors thank the support from Analytical Instrumentation Center (\# SPST-AIC10112914), SPST, ShanghaiTech University.

\section{Author contributions}

J.W., S.R., and J.X. performed the experiments. S.Z. and Q.P. performed the computational study. N.Y. collected the crystallographic data. Q.P. and X.Y. directed the project and wrote the paper.

\section{Competing interests}

The authors declare no competing interests.

\section{Additional information}

Supplementary information is available for this paper at https://doi.org/10.1038/s41467020-19294-8.

Correspondence and requests for materials should be addressed to Q.P. or X.Y.

Peer review information Nature Communications thanks the anonymous reviewer(s) for their contribution to the peer review of this work. Peer reviewer reports are available.

Reprints and permission information is available at http://www.nature.com/reprints Publisher's note Springer Nature remains neutral with regard to jurisdictional claims in published maps and institutional affiliations.

(c) (i)

Open Access This article is licensed under a Creative Commons Attribution 4.0 International License, which permits use, sharing, adaptation, distribution and reproduction in any medium or format, as long as you give appropriate credit to the original author(s) and the source, provide a link to the Creative Commons license, and indicate if changes were made. The images or other third party material in this article are included in the article's Creative Commons license, unless indicated otherwise in a credit line to the material. If material is not included in the article's Creative Commons license and your intended use is not permitted by statutory regulation or exceeds the permitted use, you will need to obtain permission directly from the copyright holder. To view a copy of this license, visit http://creativecommons.org/ licenses/by/4.0/.

(c) The Author(s) 2020 